\title{
Common resistance to Fusarium head blight in Brazilian wheat cultivars
}

\author{
Gabriela da Rocha Lemos Mendes ${ }^{1}$, Emerson Medeiros Del Ponte ${ }^{2 *}$, Ana Carla Feltrin ${ }^{3}$, Eliana Badiale-Furlong ${ }^{3}$, Antônio Costa de \\ Oliveira $^{1}$ *
}

${ }^{1}$ Federal University of Pelotas/FAEM - Dept. of Crop Science - Plant Genomics and Breeding Center, Campus Universitário, s/n - 96001-970 - Pelotas, RS - Brazil. ${ }^{2}$ Federal University of Viçosa - Dept. of Plant Pathology, Campus Universitário, s/n -36570-000 - Viçosa, MG Brazil.

${ }^{3}$ Federal University of Rio Grande/Chemistry and Food School, Av. Itália, km 08 -96201-900 - Rio Grande, RS Brazil.

*Corresponding authors <acostol@terra.com.br; delponte@ ufv.br>

Edited by: Mark L. Gleason

Received October 05, 2016

Accepted July 19, 2017
ABSTRACT: Mycotoxin levels in Fusarium head blight (FHB) infections can be difficult to quantify. The relationship between mycotoxin and disease is not consistent and it is not clear if wheatpathogen interaction is of significance in regions where more than one Fusarium species with distinct trichothecene production ability co-exists. This study aimed to investigate whether a set of eight Brazilian wheat genotypes, varying in resistance according to classification by the breeder, exhibit a common or differential resistance to Fusarium graminearum (Fgra) (deoxynivalenolproducing) and Fusarium meridionale (nivalenol-producing) (Fmer) using full-spike and central spikelet inoculation (type II resistance). Fgra was generally more aggressive than Fmer based on the percentage of diseased spikes (99 and $84 \%$, respectively) and number of diseased spikelets (mean 2.8 and 2.0, respectively) below the central spikelet. The genotype-pathogen species interaction was not significant, but there were differences between the genotypes, with BRS 194 and BRS 327 being the least and most resistant, respectively, based on severity ratings. The incidence of Fusarium-damaged kernel (FDK, \%) was not affected by species, but two genotypes (BRS Parrudo and BRS 327) showed a lower incidence of FDK. There were substantial variations in the accumulation of deoxynivalenol and nivalenol among the genotypes, reaching maxima of $691.2 \mu \mathrm{g} \mathrm{g}^{-1}$ and $355.2 \mu \mathrm{g} \mathrm{g}^{-1}$, respectively, suggesting that Fgra is a more potent producer of trichothecene. Our data confirm prior resistance classifications by the breeders and suggest that the use of a single highly aggressive Fgra isolate may be sufficient for effective screening for FHB resistance. However, further studies are needed to elucidate the accumulation of resistance to trichothecene.

Keywords: visual assessment, spray-inoculation, point-inoculation, mycotoxins

\section{Introduction}

Fusarium head blight (FHB) is one of the most damaging diseases threatening wheat worldwide and is responsible for severe reductions in grain yield and quality (McMullen et al., 2012). The disease is caused mainly by members of the $F$. graminearum species complex (FGSC), which produce trichothecene mycotoxins including deoxynivalenol (DON) and nivalenol (NIV) (Desjardins et al., 1993; McMullen et al., 2012). Regulatory agencies in major wheat-producing countries limit the maximum levels of mycotoxins in commodities. In Brazil, the maximum limit in wheat grain is set at 3000 $\mu \mathrm{g} \mathrm{kg}^{-1}$ (Anvisa, 2011). Thus far, integration of resistant cultivars and fungicide applications is the recommended approach for disease control and mycotoxin reduction. Wheat breeders have focused on cost-effective visual assessments of resistance to initial infection (Type I) and to further spreading of the disease within the spike (Type II), which has led to selection of genotypes with moderate resistance to $\mathrm{FHB}$, particularly to Type II (Rudd et al., 2001; Sneller et al., 2012). In Brazil, a number of cultivars exhibit moderate resistance, but the levels are not sufficient to prevent epidemics in a disease-conducive environment (Alves et al., 2013; Silva et al., 2010). For instance, the Brazilian cvs. Frontana and BRS Parrudo have been used as standards for moderate resistance (Caierão et al., 2014; Lemmens et al., 2004; Nicolli et al., 2015; Van Ginkel et al., 1996).
In Brazil, F. graminearum, a DON producer, is the main FHB pathogen, followed by F. meridionale, which produces mainly NIV but also small amounts of DON (Nicolli et al., 2015). Whereas $F$. graminearum is dominant overall ( $>85 \%$ frequency) in Brazil, F. meridionale is an important species (up to $30 \%$ frequency) in the state of Paraná, due to the fact that maize, which is widely cultivated in this state, is another host of this pathogen (Astolfi et al., 2012; Del Ponte et al., 2015). Resistance to FHB was suggested to be common across several Fusarium species, including those within FGSC, but the evaluation was limited to wheat genotypes in Eastern Europe (Mesterházy et al., 2005). Previous controlled environment studies in Brazil have indicated that resistance in two cultivars have been influenced by the species of FHB pathogen used for inoculation, suggesting a genotype-species interaction effect (Spolti et al., 2012). Thus, we aimed to characterize the reaction for a set of eight Brazilian wheat genotypes of known resistance when challenged by the two most prevalent FGSC pathogen species causing FHB in Brazil.

\section{Materials and Methods}

\section{Wheat genotypes}

Eight wheat genotypes were selected for this study based on their known reaction to FHB and extent of use in southern Brazil. Five genotypes had a moderately resistant (MR) reaction (BRS 327, BRS Parrudo, 
BRS Guamirim, Frontana and TBIO Alvorada) and three had a susceptible (S) reaction (BRS 194, Quartzo and CD 105) as demonstrated by both field and controlledenvironment experiments (Alves et al., 2013; Nicolli et al., 2015).

\section{Fungal isolates and inoculum production}

The two isolates used in this study, each representing one of the two species most commonly associated with FHB in Brazil (Del Ponte et al., 2015), F. graminearum and $F$. meridionale, were selected based on their known aggressiveness and toxigenic potential determined in previous studies (Nicolli et al., 2015; Spolti et al., 2012). They are deposited at the Lavras Mycological collection (CML) under the following codes: CML 3344 (F. meridionale strain) and CML 3066 (F. graminearum strain). Inoculum was produced in SNA (Spezieller Nährstoffarmer Agar) media as described (Spolti et al., 2012) and consisted of a suspension of $10^{5}$ macroconidia $\mathrm{mL}^{-1}$.

\section{Plant growth and inoculation treatments}

For each genotype, eight plastic pots $(1 \mathrm{~L})$ containing soil substrate (equal parts of humus:soil:vermiculite) fertilized with macronutrients (NPK in the ratio of 10:10:10) were sown with ten seeds each. The pots were maintained in a greenhouse from planting to flowering for approximately 3 months at $25 \pm 5{ }^{\circ} \mathrm{C}$ at an average relative humidity of around $60 \%$. Inoculations were performed at full flowering when plants are most susceptible (Spolti et al., 2012).

Two methods of inoculation were used in separate experiments. In the first full-spike spray-inoculation was used to simulate conditions resembling natural infection (Miedaner, Moldovan and Ittu, 2003), and the following responses were evaluated: 1) incidence of disease (proportion of diseased spikes), used to infer resistance to initial infection (Type I); 2) Fusarium-damaged kernels, through the visual assessment of symptomatic kernels; and 3) accumulation of the trichothecenes DON and NIV in grains. The second method, in a separate experiment, was central-spikelet inoculation, which allows for assessing type II resistance; i.e. resistance to spreading from a point of infection (Bai and Shaner, 2004; Mesterházy et al., 2003).

\section{Spray-inoculation assay}

Wheat spikes at the full flowering stage were sprayed individually with $3 \mathrm{~mL}$ of conidial suspension using a hand-sprayer. The conidial suspension was prepared on the day of inoculation and conidia germination was $>80 \%$ during inoculation. After inoculation, plants were kept in a moist chamber at $25 \pm 2{ }^{\circ} \mathrm{C}$ and a relative humidity of $95 \pm 2 \%$ for $48 \mathrm{~h}$. Next, the plants were moved into a growth chamber at $25^{\circ} \mathrm{C}$ with a $12 \mathrm{~h}$ alternating dark/light cycle. The proportion of symptomatic spikelets, also known as the FHB index, were assessed visually at 5, 10 and 15 days after the 2-day incubation period. At 25 to 30 days after flowering, the spikes were harvested, hand-threshed and dried uniformly to $13 \%$ moisture. The incidence of Fusarium-damaged kernels (FDK, \%), i.e., small, shrunken, and whitish-pink in color, was determined by dividing the number of symptomatic grains by the total number of grains harvested from each pot. Concentration levels of deoxynivalenol (DON) and nivalenol (NIV) were determined using HPLC-UV. The validation parameters evaluated were the limit of detection (LOD), which refers to the lowest concentration of mycotoxin that can be detected, and recovery percentage, i.e., the proportion of the amount of mycotoxins present in or added to the grain material, which is extracted and quantified. The method used showed a $16.7 \mu \mathrm{g} \mathrm{kg}^{-1}, 33.3 \mu \mathrm{g} \mathrm{kg}-1$ of LOD for DON and NIV, respectively, and $89 \%$ and $76 \%$ recovery for DON and NIV, respectively (E. Seus, Federal University of Rio Grande/Chemistry and Food School, Rio Grande do Sul, Brazil, unpublished data).

\section{Central-spikelet inoculation assay}

At full flowering (> $>0 \%$ of visible anthers), 10 $\mu \mathrm{L}$ of the macroconidia suspension was gently applied, using a micropipette, to a floret of a central spikelet in a spike, usually the fifth spikelet from the top to the base of the spike. After inoculation, the plants were maintained in a growth chamber under the same conditions as the previous experiment. The number of symptomatic spikelets below the inoculation point was counted at 5, 10 and 15 days after the 2-day moist chamber incubation following inoculation (early milk to early dough stages). Diseased spikelets above the inoculation point were not counted because symptoms could not be distinguished from premature death of tissue due to blocking of vessels at lower points on the spike (Horevaj et al., 2011). The area under the disease progress curve (based on counts of symptomatic spikelets) was calculated for each genotype in order to compare the type II resistance among the genotypes.

\section{Experimental design and data analysis}

Both experiments were conducted in a factorial (eight wheat genotypes $\times$ two fungal species) completely randomized design with eight replications (pots) per treatment. A non-inoculated treatment was included in the experiment as a negative control. Homocedasticity and normality in the fitted residuals data from both experiments were assessed based on visual inspection of the residuals and Levene and Shapiro-Wilks tests, respectively. Since each experiment was conducted twice an Anova model was used initially, considering the experiment as a factor in the analysis, to indicate whether data from both experiments could be combined for analysis. For the spray-inoculation experiment, a generalized linear mixed model was fitted to data on disease severity only at 5 days after inoculation, because at later times severity was very high and uniform across treatments. The experiment and replications were treated as a ran- 
dom factor and wheat genotype and fungal species as fixed effects. For FDK, the assumptions of parametric Anova were not met, and thus the Kruskal-Wallis test was used to compare single effects of wheat genotypes and species. Due to very small amounts of grain mass obtained for each replicate in the spray-inoculation experiment, grains from all replicates (pots) of a treatment were combined for mycotoxin analysis, and thus the means of DON and NIV could not be estimated and compared across treatments. All statistical analyses were performed in the $\mathrm{R}$ statistical computing environment. The mixed models were fitted using the lmer function of lme4 package of $\mathrm{R}$. Treatment means were calculated using the lsmeans function of lsmeans $\mathrm{R}$ package and compared based on Tukey's test $(p \leq 0.05)$. Additionally, wheat genotypes were unambiguously discriminated based on the Scott-knot test ( $p \leq 0.05)$.

\section{Results}

\section{Spray inoculation assay}

Fusarium head blight symptoms were observed at high incidence (>70\%) in the spikes of all wheat genotypes at 5 days after the 2-day incubation, especially in plants inoculated with $F$. graminearum (Table $1)$; the mean FHB index averaged $99 \%$ among wheat genotypes $(p>0.05)$. Mean severity in wheat genotypes inoculated with $F$. meridionale averaged $84 \%$ and three groups were defined based on Tukey's test ( $p \leq 0.05)$, with BRS Parrudo and Quartzo showing the lowest and highest severity means, respectively.

There was no effect of fungal species on FDK levels $(p>0.05)$. Two groups of wheat genotypes were defined based on the Kruskal-Wallis test. Frontana and BRS Parrudo differed significantly from the other genotypes, with FDK levels of $23 \%$ and $21 \%$, respectively.

Table 1 - Fusarium head blight (FHB) severity, incidence of Fusarium-damaged kernels (FDK), and trichothecene mycotoxin (DON = deoxynivalenol and NIV = nivalenol) concentrations in wheat genotypes inoculated with a Fusarium meridionale (Fmer) or $F$. graminearum (Fgra) isolate during the full flowering stage and maintained at $25^{\circ} \mathrm{C}$ for up to 5 days, following a 2-day moist incubation period after inoculation.

\begin{tabular}{|c|c|c|c|c|c|}
\hline \multirow{2}{*}{ Genotype } & \multicolumn{2}{|c|}{ FHB Severity } & \multirow{2}{*}{ FDK } & \multicolumn{2}{|c|}{ Trichothecenes } \\
\hline & Fgra & Fmer & & DON (Fgra & JIV (Fmer) \\
\hline & \multicolumn{5}{|c|}{$\longrightarrow \%-\mu \mathrm{g} \mathrm{g}^{-1} \longrightarrow$} \\
\hline BRS 194 & $100.0 \mathrm{~A}^{\mathrm{ns}}$ & $79.9 \mathrm{Bbc}$ & $40.6 \mathrm{a}$ & 182.7 & 5.9 \\
\hline BRS 327 & $100.0 \mathrm{~A}$ & 86.7 Bbc & $38.8 \mathrm{ab}$ & 92.1 & 6.6 \\
\hline BRS Guamirim & $99.2 \mathrm{~A}$ & $90.2 \mathrm{Abc}$ & 51.8 a & 307.3 & 37.6 \\
\hline BRS Parrudo & $99.8 \mathrm{~A}$ & $64.6 \mathrm{Bc}$ & $21.0 \mathrm{~b}$ & 64.3 & 10.8 \\
\hline CD 105 & $99.7 \mathrm{~A}$ & 93.6 Abc & $71.8 \mathrm{a}$ & 45.3 & 355.2 \\
\hline Frontana & $100.0 \mathrm{~A}$ & 80.6 Babc & $22.6 b$ & 337.9 & 4.3 \\
\hline Quartzo & $99.8 \mathrm{~A}$ & $94.9 \mathrm{Aa}$ & $86.1 \mathrm{a}$ & 691.2 & 82.4 \\
\hline TBIO Alvorada & $98.0 \mathrm{~A}$ & 83.0 Babc & $97.1 \mathrm{a}$ & 186.5 & 125.8 \\
\hline
\end{tabular}

Mean values followed by the same uppercase letter between columns and lowercase between rows do not differ by Tukey's test ( $p \leq 0.05)$; ns $=$ not significant.
BRS 327 did not differ from these two least damaged genotypes, but its FDK mean was also similar to the other genotypes, ranging from $39 \%$ to $97 \%$.

The DON and NIV trichothecenes were found in wheat kernels from the spray-inoculated experiments at various levels across the genotypes. The DON and NIV levels across the genotypes were very high, on average, reaching $238.4 \mu \mathrm{g} \mathrm{g}^{-1}$ and $78.5 \mathrm{\mu g} \mathrm{g}^{-1}$, respectively. In all but one genotype (CD 105), DON levels were higher than NIV levels. There was a negative but non-significant correlation between DON and NIV levels $\mid r=-0.21, p$ $=0.6)$. DON levels were $>300 \mu \mathrm{g} \mathrm{g}^{-1}$ in Quartzo, Frontana and BRS Guamirim; < $100 \mu \mathrm{g} \mathrm{g}^{-1}$ in BRS 327, BRS Parrudo and CD 105 and intermediate for BRS 194 and TBIO Alvorada (Table 1). Very high NIV levels (> $350 \mu \mathrm{g}$ $\mathrm{g}^{-1}$ ) were found in CD 105, followed by TBIO Alvorada and Quartzo (NIV > $82 \mu \mathrm{g} \mathrm{g}^{-1}$ ). Frontana, BRS 194 and BRS 327 had NIV levels $<7 \mu \mathrm{g} \mathrm{g}^{-1}$. When total trichothecenes (DON + NIV) were considered, the lowest levels were found in BRS Parrudo and BRS $327 /<100 \mu \mathrm{g}$ $\left.\mathrm{g}^{-1}\right)$. The highest total of trichothecenes was found in Quartzo (> $\left.770 \mu \mathrm{g} \mathrm{g}^{-1}\right)$.

\section{Central-spikelet inoculation assay}

FHB symptoms below the inoculation point were found in all genotypes inoculated with both species. However, symptoms induced by $F$. graminearum progressed faster than those induced by $F$. meridionale, generally leading to increased severity levels across all genotypes, especially during the first 10 days after inoculation (Figure 1A). The Anova model fitted to the area under the disease progress curve (AUDPC) corroborated $(p=0.58)$ visual inspection of the progress

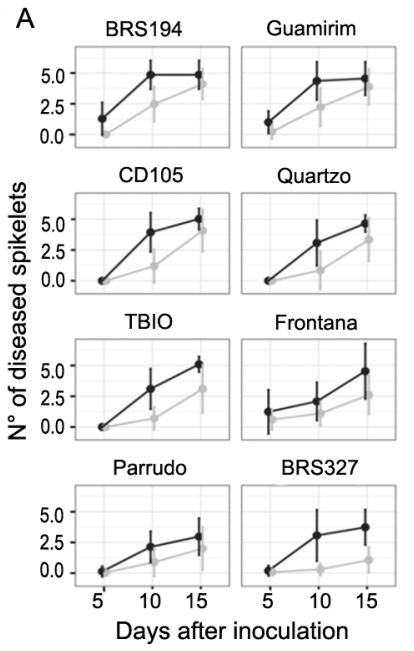

B

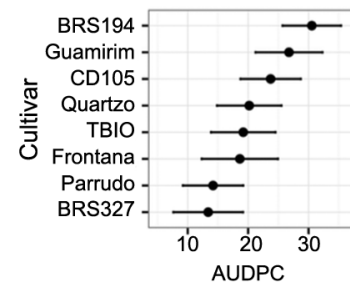

C

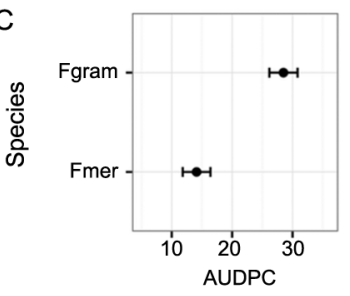

Figure 1 - Number of diseased spikelets below the central floret of wheat genotypes inoculated with a Fusarium meridionale (gray lines) or an F. graminearum (black lines) isolate (A) and the calculated area under the disease (number of diseased spikelets) progress curve (AUDPC) for each cultivar (B) and inoculated species (C). 
curves which suggested a non-significant effect of cultivar $\times$ species interaction. However, host genotype $(p$ $<0.001)$ and pathogen species ( $p<0.001)$, significantly affected AUDPC. The lsmeans estimate of AUDPC for $F$. graminearum was two times higher than that for $F$. meridionale (Figure $1 \mathrm{C}$ ); mean final severity values ranged from 20 to $40 \%$ for the former and from 4 to $23 \%$ for the latter across the wheat genotypes. Lsmeans estimates, irrespective of the species, ranged from 13 to 30 $\%$ across the eight genotypes. The Scott-knot test separated the cultivars into two groups, with BRS 194, BRS Guamirim and CD105 being more susceptible than the others (Figure 1B). BRS Parrudo and Frontana exhibited the lowest AUDPC when these two species were considered (Figure 1A), whereas BRS 327 was the least susceptible because of the slower progress of the symptoms induced by the Fmer isolate (Figure 1A).

\section{Discussion}

This study provides the first detailed analysis of different types of FHB resistance for a set of wheat genotypes challenged by the two most common FHB pathogens in Brazil, which differ in the type of trichothecene produced. A number of the selected genotypes are currently grown in large acreage and possess different levels of resistance as determined by breeders using visual assessments during field screening (Schlang and Duveiller, 2012).

We found that one of the most significant traits commonly determined in the less susceptible commercial genotypes worldwide, type II resistance, or resistance to disease spread, did not depend on the cultivarpathogen interaction, meaning that the ranking of the genotypes did not depend on the pathogen species. This is important information for breeders, and agrees with the results of a European study (Mesterházy et al., 2005). Based on our results, the selection of superior wheat genotypes could thus be performed using a single aggressive isolate from either species, preferably the most aggressive one, or $F$. graminearum of the 15-ADON genotype, which has been shown to be highly adaptable as a wheat pathogen (Del Ponte et al., 2015; Nicolli et al., 2015). In contrast, F. meridionale has been suggested as being more adapted to infecting maize, given the higher frequency in this crop than $F$. graminearum (Kuhnem et al., 2016).

The inoculation experiments were performed under conditions which are very conducive to the development of disease. Therefore, when using high inoculum pressure applied as spray toward the full spikes, severity reached $100 \%$ at 5 days after inoculation with the exception of BRS Parrudo (> $80 \%$ ). Nevertheless, the portion of Fusarium-damaged kernels in two genotypes, including Frontana, an old cultivar which is considered a standard for resistance, and BRS Parrudo, were the least damaged, suggesting a type IV resistance (Mesterházy, 1995; Mesterházy et al., 1999), or the ability of the genotypes to tolerate damage, though not suppress symptoms on the spikes. In fact, previous studies have shown that Frontana exhibited low levels of damage in kernels caused by Fusarium species, which might be due to a resistance mechanism (Burlakoti et al., 2009; Wiśniewska et al., 2004).

Due to the very conducive environment during the experiments, most genotypes spray-inoculated with the DON-producer $F$. graminearum isolate exhibited high severity, which masked differences between the cultivars, and prevented making conclusions regarding type I resistance. The high levels of severity from $F$. graminearum inoculations, compared to $F$. meridionale, may relate to high potential for trichothecene production by $F$. graminearum; DON levels were around three times higher than NIV which resulted from inoculations with $F$. meridionale. In planta, trichothecenes are known to act by blocking the synthesis of proteins and favor pathogen colonization in host tissue (Desjardins et al., 1993; Desjardins et al., 1996). Moreover, DON is recognized as a virulence factor during pathogenesis, with more symptoms being associated with higher DON production, whereas NIV in wheat is produced in smaller quantities than DON (Desjardins et al., 2004).

Although resistance among the genotypes could not be discriminated using spray inoculations, the trichothecene concentration found in the kernels was highly variable. However, statistical evidence could not be assessed due to limitation in grain mass, which required that replicates were combined into a single sample. Nevertheless, the genotypes with lower numeric values of DON and NIV were BRS 194 and BRS 327, suggesting a mechanism of DON degradation or another factor limiting mycotoxin production in these genotypes, which should be assessed in future research. In general, DON levels were higher than NIV, confirming previous findings (Nicolli et al., 2015). However, for a number of genotypes not previously evaluated for this trait, such as CD 105, NIV levels were seven times higher than DON for reasons that should be further explored. Frontana, although exhibiting relatively low levels of disease severity and damage in kernels, showed the second largest amount of DON but very low levels of NIV. This was unexpected given a previous report of Frontana's ability to degrade deoxynivalenol in embryo cultures (Miller and Arnison, 1986). However, there is evidence that in vitro studies on mycotoxin accumulation correlate poorly with in vivo experiments, which will require further experimentation to clarify (Gosman et al., 2005; Malbrán et al., 2014; Walker et al., 2001).

In general, our data on mycotoxin accumulation agree with previous studies that have also shown a weak association between visual symptoms and the accumulation of mycotoxin (Arseniuk et al., 1999; Mesterházy et al., 1999; Wiśniewska et al., 2004). Therefore, when selecting for mycotoxin resistance, it would be instructive to include data on mycotoxin accumulation as a 
component of the breeding selection criteria (Arseniuk et al., 1999; Ji et al., 2015; Jin et al., 2014; Schlang and Duveiller, 2012). To overcome the high costs associated with mycotoxin analysis, assessments of FDK, in addition to being a more affordable method, usually correlate more strongly with mycotoxin levels than visual assessment of the wheat spikes, and could be used as a surrogate variable to select for resistance to mycotoxin (Mesterházy et al., 2005; Sneller et al., 2012). In conclusion, our study confirms significant differences between two members of the $F$. graminearum species complex related to their ability to cause FHB in wheat, irrespective of the cultivar. Out of the genotypes evaluated in this study, BRS Parrudo and BRS 327 were among the most resistant overall, exhibiting generally lower levels of symptoms on both spike and kernel as well as lower levels of trichothecenes compared to the other cultivars. The mechanisms involved in the resistance by these genotypes merit further investigation.

\section{References}

Agência Nacional de Vigilância Sanitária [ANVISA]. 2011. Resolution $\mathrm{n}^{0} 7$, maximum permissible levels for mycotoxins in food - Resolução $\mathrm{n}^{\circ}$ 7, limites máximos tolerados (LMT) para micotoxinas em alimentos. Accessible at: http://bvsms. saude.gov.br/bvs/saudelegis/anvisa/2011/res0007_18_02_2011_ rep.html [Accessed July 7, 2016] (in Portuguese).

Alves, R.H.; Nora T.D.; Franco, F.D.A.; Carlos A.; Stangarlin, R. 2013. Type I and type II resistance reaction to FHB in wheat cultivars. Summa Phytopathologica 39: 167-171 (in Portuguese, with abstract in English).

Arseniuk, E.; Foremska, E.; Góral, T.; Chelkowski, J. 1999. Fusarium head blight reactions and accumulation of deoxynivalenol (DON) and some of its derivatives in kernels of wheat, triticale and rye. Journal of Phytopathology 147: 577590.

Astolfi, P.; Reynoso, M.M.; Ramirez, M.L.; Chulze, S.N.; Alves, T.C.; Tessmann, D.J.; Del Ponte, E.M. 2012. Genetic population structure and trichothecene genotypes of Fusarium graminearum isolated from wheat in southern Brazil. Plant Pathology 61: 289-295.

Bai, G.; Shaner, G. 2004. Management and resistance in wheat and barley to fusarium head blight. Annual Review of Phytopathology 42: 135-161.

Burlakoti, R.R.; Mergoum, M.; Kianian, S.F.; Adhikari, T.B. 2009. Combining different resistance components enhances resistance to Fusarium head blight in spring wheat. Euphytica 172: $197-205$.

Caierão, E.; Scheeren, P.L.; Silva, M.S.; Castro, R.L. 2014. History of wheat cultivars released by Embrapa in forty years of research. Crop Breeding and Applied Biotechnology 14: 216223.

Del Ponte, E.M.; Spolti, P.; Ward, T.; Gomes, L.B.; Nicolli, C.P.; Kuhnem, P.R.; Da Silva, C.N.; Tessmann, D.J. 2015. Regional and field-specific factors affect the composition of Fusarium head blight pathogens in subtropical no-till wheat agroecosystem of Brazil. Phytopathology 105: 246-254.
Desjardins, A.E.; Hohn, T.M.; McCormick, S.P. 1993. Trichothecene biosynthesis in Fusarium species: chemistry, genetics, and significance. Microbiological Reviews 57: 595604.

Desjardins, A.E.; Jarosz, A.M.; Plattner, R.D.; Alexander, N.J.; Brown, D.W.; Jurgenson, J.E. 2004. Patterns of trichothecene production, genetic variability, and virulence to wheat of Fusarium graminearum from smallholder farms in Nepal. Journal of Agricultural and Food Chemistry 52: 6341-6346.

Desjardins, A.E.; Proctor, R.H.; Bai, G.; McCormick, S.P.; Shaner, G.; Buechley, G.; Hohn, T.M. 1996. Reduced virulence of trichothecene-nonproducing mutants of Gibberella zeae in wheat field tests. Molecular Plant-Microbe Interactions 9: 775-781.

Gosman, N.; Chandler, E.; Thomsett, M.; Draeger, R.; Nicholson, P. 2005. Analysis of the relationship between parameters of resistance to Fusarium head blight and in vitro tolerance to deoxynivalenol of the winter wheat cultivar WEK0609. European Journal of Plant Pathology 111: 57-66.

Horevaj, P.; Gale, L.R.; Milus, E.A. 2011. Resistance in winter wheat lines to initial infection and spread within spikes by deoxynivalenol and nivalenol chemotypes of Fusarium graminearum. Plant Disease 95: 31-37.

Ji, F.; Wu, J.; Zhao, H.; Xu, J.; Shi, J. 2015. Relationship of deoxynivalenol content in grain, chaff, and straw with Fusarium head blight severity in wheat varieties with various levels of resistance. Toxins 7: 728-742.

Jin, F.; Bai, G.; Zhang, D.; Dong, Y.; Ma, L.; Bockus, W.; Dowell, F. 2014. Fusarium-damaged kernels and deoxynivalenol in Fusarium-infected U.S. winter wheat. Phytopathology 104: 472-478.

Kuhnem, P.R.; Ward, T.J.; Silva, C.N.; Spolti, P.; Ciliato, M.L.; Tessmann, D.J.; Del Ponte, E.M. 2016. Composition and toxigenic potential of the Fusarium graminearum species complex from maize ears, stalks and stubble in Brazil. Plant Pathology 65: 1185-1191.

Lemmens, M.; Griesser, M.; Scholz, U.; Schondelmaier, J.; Buerstmayr, H.; Steiner, B. 2004. Molecular mapping of resistance to Fusarium head blight in the spring wheat cultivar Frontana. Theoretical and Applied Genetics 109: 215-224.

Malbrán, I.; Mourelos, C.A.; Girotti, J.R.; Balatti, P.A.; Lori, G.A. 2014. Toxigenic capacity and trichothecene production by Fusarium graminearum isolates from Argentina and their relationship with aggressiveness and fungal expansion in the wheat spike. Phytopathology 104: 357-364.

McMullen, M.P.; Bergstrom, G.C.; De Wolf, E.; Dill-Macky, R.; Hershman, D.E.; Shaner, G.; Van Sanford, D.A. 2012. A unified effort to fight an enemy of wheat and barley: Fusarium head blight. Plant Disease 96: 1712-1728.

Mesterházy, A. 1995. Types and components of resistance to Fusarium head blight of wheat. Plant Breeding 114: 377-386.

Mesterházy, A.; Bartók, T.; Kászonyi, G.; Varga, M.; Tóth, B.; Varga, J. 2005. Common resistance to different Fusarium spp. causing Fusarium head blight in wheat. European Journal of Plant Pathology 112: 267-281.

Mesterházy, A.; Bartók, T.; Lamper, C. 2003. Influence of wheat cultivar, species of Fusarium, and isolate aggressiveness on the efficacy of fungicides for control of Fusarium head blight. Plant Disease 87: 1107-1115. 
Mesterházy, A.; Bartók, T.; Mirocha, C.G.; Komoróczy, R. 1999. Nature of wheat resistance to Fusarium head blight and the role of deoxynivalenol for breeding. Plant Breeding 118: 97110.

Miller, J.D.; Arnison, P.G. 1986. Degradation of deoxynivalenol by suspension cultures of the Fusarium head blight resistant wheat cultivar Frontana. Canadian Journal of Plant Pathology 8: $147-150$.

Nicolli, C.P.; Spolti, P.; Tibola, C.S.; Fernandes, J.M.C.; Del Ponte, E.M. 2015. Fusarium head blight and trichothecene production in wheat by Fusarium graminearum and F. meridionale applied alone or in mixture at post-flowering. Tropical Plant Pathology 40: 134-140.

Rudd, J.C.; Horsley, R.D.; McKendry, A.L.; Elias, E.M. 2001. Host plant resistance genes for Fusarium head blight : sources, mechanisms, and utility in conventional breeding systems. Crop Science 41: 620-627.

Schlang, N.; Duveiller, E. 2012. Current approaches and utilization of new screening techniques for evaluation of FHB resistance at CIMMYT. Plant Breeding and Seed Science 64: 89-103.

Silva, M.S.; Só, M.; Caierão, E.; Scheeren, P.L.; Eichelberger, L.; Junior, A.N.; Zavariz, M. 2010. Cultivar release BRS 327: a new bread wheat cultivar. Crop Breeding and Applied Biotechnology 10: 370-373.
Sneller, C.; Guttieri, M.; Paul, P.; Costa, J.; Jackwood, R. 2012. Variation for resistance to kernel infection and toxin accumulation in winter wheat infected with Fusarium graminearum. Phytopathology 102: 306-314.

Spolti, P.; Barros, N.C.; Gomes, L.B.; Santos, J.; Del Ponte, E.M. 2012. Phenotypic and pathogenic traits of two species of the Fusarium graminearum complex possessing either 15-ADON or NIV genotype. European Journal of Plant Pathology 133: 621629.

Van Ginkel, M.; Van der Shaar, W.; Zhuping, Y.; Rajaram, S. 1996. Inheritance of resistance to scab in two wheat cultivars from Brazil and China. Plant Disease 80: 863-867.

Walker, S.L.; Leath, S.; Hagler, W.M.; Murphy, J.P. 2001. Variation among isolates of Fusarium graminearum associated with Fusarium head blight in North Carolina. Plant Disease 85: 404410.

Wiśniewska, H.; Perkowski, J.; Kaczmarek, Z. 2004. Scab response and deoxynivalenol accumulation in spring wheat kernels of different geographical origins following inoculation with Fusarium culmorum. Journal of Phytopathology 152: 613621. 